\title{
A educação como empoderamento na ótica do desenvolvimento: uma discussão de modelos
}

\author{
Education as empowerment in the point of view of development: a discussion of models
}

\author{
Manuel Gonçalves Barbosa \\ Instituto de Educação-Universidade do Minho
}

\begin{abstract}
Resumo
Apresentamos nesta comunicação uma tese de ressignificação da educação como empoderamento tendo como foco uma agenda de desenvolvimento justo, digno e inclusivo, e equacionamos os seus principais tipos ou modelos, partindo do princípio que o empoderamento, pelo facto de remeter para diversas conotações ideológicas, não permite almejar consensos quando se trata de o tomar como sinal distintivo ou imagem de marca de uma educação cuja aposta principal é a promoção de um desenvolvimento humano verdadeiramente empenhado em corresponder às expectativas normativas das pessoas em termos de justiça, respeito, dignidade, liberdade e direitos fundamentais para todos.

Palavras-chave: educação, desenvolvimento,
\end{abstract} empoderamento, modelos

\begin{abstract}
We present in this communication a thesis of ressignification of education as empowerment focusing on a fair development agenda, dignified and inclusive, and we equate their main types or models, assuming that the empowerment, because of referring to several ideological connotations, does not allow to aim for consensus when it comes to taking it as a distinctive sign or as a brand image of an education whose main focus is the promotion of a human development truly committed to meet the normative expectations of people in terms of justice, respect, dignity, freedom and fundamental rights for everyone.

Keywords: education, development, empowerment, models
\end{abstract}

Diante da possibilidade de assistirmos, muito em breve, à definição de uma nova agenda global para o desenvolvimento, certamente, como tudo indica, dando centralidade às pessoas, aos seus problemas e às suas aspirações, e face à iminência de se reafirmar, mais uma vez, o carácter estratégico da educação na realização de agendas desse tipo, conviria averiguar se é chegado o momento de reinvestir a educação com o significado de empoderamento e se essa operação de ressemantização, de amplas consequências teóricas e práticas, pode gerar consensos alargados na comunidade de todos aqueles e aquelas que pensam e fazem educação nos mais variados contextos e ambientes. Como hipótese de trabalho e linha condutora de uma reflexão sobre o fenómeno educativo, a ressignificação da educação como empoderamento na ótica do desenvolvimento pode ser interessante para abrir novos horizontes de investigação educacional e, espera-se, novas formas ou modalidades de operacionalização da educação com pessoas, grupos e coletividades. Ainda assim, importa estar precavido, pois essa articulação da educação com o empoderamento no quadro de orientações programáticas sobre desenvolvimento pode tornar-se equívoca e fonte de debates sem sentido se não se realiza um trabalho de elucidação de tendências e perspetivas, seja no que concerne a relação entre a educação e o desenvolvimento, relação que pode levar, como esperamos mostrar, a abrir a «caixa negra» do empoderamento, seja no que concerne a constituição da educação como ato de empoderamento, quer dizer, como processo que investe no reforço ou aquisição de poder de sujeitos individuais e, eventualmente, de sujeitos coletivos. Só a esta luz cabe discutir os vários modelos que dão corpo à educação como empoderamento e se é realista almejar um consenso alargado em torno desse novo significado de educação no quadro das perspetivas mais abrangentes de desenvolvimento humano. A conclusão deste exercício reflexivo é que tal consenso se revela enganador e a vários títulos problemático, pois estão em presença, digladiando-se, diferentes conceções ideológicas de empoderamento. Seja como for, e numa perspetiva suficientemente ampla de educação para o desenvolvimento, faz todo o sentido ressignificar a educação como processo de empoderamento.

\section{Educação e desenvolvimento: abrindo a «caixa negra» do empoderamento}

Um dos lugares comuns mais correntemente afirmados é que não há educação que não seja, de uma ou de outra forma, ajuda ao desenvolvimento e que este, enquanto evolução positiva para um estado desejado, não pode passar sem o contributo da educação. Isto é o que se repete, insistentemente, em toda uma vasta retórica acerca da relação simbiótica entre educação e desenvolvimento, particularmente nos textos onusianos. São legião, nestes textos normativos, afirmações segundo as quais a educação é essencial ao desenvolvimento, que é mesmo a chave ou a condição sine qua non do desenvolvimento, sendo necessário, por essa fundamental razão, revalorizar o papel estratégico da educação na busca do desenvolvimento pessoal, social e comunitário.

Quem assim se pronuncia acerca da educação e do desenvolvimento, seja em resoluções das Nações Unidas sobre desenvolvimento humano e desenvolvimento sustentável, designadamente a Resolução n. ${ }^{0}$ 57/254 na 
qual se proclama a Década da Educação das Nações Unidas para o Desenvolvimento Sustentável, seja em planos de ação que essa mesma agência elabora para os Estados-membros sobre essa e outras matérias afins, parece esquecer que esse tema, o da educação e desenvolvimento, está envolto em polémicas desconcertantes, causando não poucos embaraços quando queremos saber a que tipo de desenvolvimento se vincula a educação. Que a educação, enquanto muleta do progresso, deva ser colocada ao serviço do desenvolvimento e que precise de se assumir, nessa função, para ter relevância social, é assunto que não levanta problemas. O que causa problemas, certamente mais do que nunca, face à proliferação de conceções divergentes de desenvolvimento, ou de agendas/narrativas a seu respeito, é o alinhamento da educação e, portanto, o seu casamento, com determinada modalidade de desenvolvimento - ou de pós-desenvolvimento como querem os adversários do modelo dominante de desenvolvimento, isto é, o desenvolvimento cuja agenda/narrativa se consubstancia no crescimento económico medido em termos de progressividade do Produto Interno Bruto per capita.

Essas visões despolitizadas, ou insuficientemente politizadas, típicas de um «consenso mole», acerca da relação entre educação e desenvolvimento, ajudam a esquecer que o «desenvolvimento é um conceito normativo» (Nussbaum, 2012: 69) e que, por esse facto, é um conceito polémico e amplamente disputado. Sob a roupagem aparentemente neutra do desenvolvimento há sempre uma agenda escondida e uma narrativa concomitante. Importa, pois, desvelar as agendas/narrativas que se ocultam por detrás do termo «desenvolvimento» para não sermos reféns de «significações imaginárias» (Castoriadis, 2005: 65) que não queremos ou que consideramos indesejáveis.

A bem da elucidação filosófica que interessa de sobremaneira a uma cidadania adulta, isto é, informada e senhora de si, convém mostrar que o desenvolvimento, na sua natureza intrinsecamente normativa, remete para horizontes de significado não só distintos como conflituantes entre si. Não é certamente a mesma coisa identificar o desenvolvimento com o crescimento económico, e com todas as consequências que daí derivam, e significá-lo para além desse reducionismo, tomando-o como desenvolvimento humano, na linha do Programa das Nações Unidas para o Desenvolvimento (1990), ou como desenvolvimento sustentável, na sequência das Cimeiras da Terra e do Relatório da Comissão Mundial sobre Meio Ambiente e Desenvolvimento de 1987.

O desenvolvimento, relativamente ao qual se pensa a educação, apresenta de facto muitas identidades e apelidos, gerando à sua volta uma grande cacofonia de agendas e narrativas. Antes de mais, a agenda/narrativa do crescimento económico contínuo, ou do crescimento indefinido da prosperidade material, desde há muito tempo prevalecente na orientação das políticas públicas, e que consiste basicamente em «assimilar felicidade e PIB» (Latouche, 2011: 48). Ou seja, quanto maior a progressão do «valor monetário da produção mercantil e não mercantil» (Méda, 2013: 92) de um país ou região, maior o bem-estar ou a felicidade da população. Esta fixação no primado do rendimento e da riqueza, além de esconder outras dimensões da vida humana, igualmente necessárias à felicidade e ao bem-estar, tem o grande defeito de não levar em devida conta a sua insustentabilidade, quer em termos ecológicos ou ambientais, já que remete para um desenvolvimento assente na exploração desenfreada dos recursos naturais, quer em termos económicos e sociais, não só por gerar recorrentes instabilidades macroeconómicas como também por ignorar, ou fazer vista grossa, a uma justa distribuição da riqueza (Jackson, 2011: 214).

De resto, e do ponto de vista da sua articulação com a educação, o que esse modelo de desenvolvimento acarreta, talvez mais hoje do que no passado, como alerta Martha Nussbaum em Not for profit. Why democracy needs the humanities (2010), é o brutal estreitamento do currículo de formação das jovens gerações, presentemente mais interessado em valorizar e em cultivar as qualificações técnicas especializadas que as tornam competitivas no mercado de trabalho do que em dar lugar de destaque à promoção de capacidades que são essenciais à saúde da democracia e a uma aproximação construtiva aos mais preocupantes problemas do mundo contemporâneo, tais como a capacidade de pensamento crítico, ou, ainda, a capacidade de ultrapassar os interesses locais para enfrentar os mundiais e a capacidade de reagir com empatia às dificuldades vividas por outras pessoas.

A alternativa a essa agenda/narrativa que equipara, de bom grado, o conceito de desenvolvimento com a démarche do crescimento sem entraves, é aquilo a que se pode chamar, numa designação acomodatícia de várias sensibilidades e posições próximas, a agenda/narrativa do desenvolvimento humano. Mais do que a prosperidade material e os índices de consumo, o que importa nesta nova agenda/narrativa do desenvolvimento é a efetiva melhoria da qualidade de vida das pessoas, medida não em termos de Produto Interno Bruto ou sequer, e já num registo eminentemente utilitarista, em termos de satisfação de preferências, mas em termos de liberdades ou capacidades e bem assim de direitos humanos, inclusive o direito humano ao desenvolvimento sustentável (Palop, 2011: 89), tal como é promovido pelo ecologismo nas suas ações em prol de uma nova racionalidade do desenvolvimento, necessariamente mais ecológica do que económica. $\mathrm{O}$ real propósito do desenvolvimento humano é o desabrochamento da pessoa, pois o que verdadeiramente importa são as pessoas: "As pessoas é que importam em última instância; os ganhos económicos apenas constituem meios instrumentais para as vidas humanas, as quais são os seus fins. A finalidade do desenvolvimento global - como a finalidade de uma boa política à escala nacional - consiste em fazer com que as pessoas vivam vidas plenas e criativas, em desenvolver o seu potencial de modo a dar origem a uma existência significativa de acordo com a igual dignidade de todos os individuos” (Nussbaum, 2012: 217).

A pessoa, e não propriamente os benefícios económicos, é que se perfila como verdadeira agenda/narrativa do desenvolvimento e, por extensão, da 
própria educação. A educação e o desenvolvimento, percecionados numa estreita relação dentro dessa conceção, colocam o foco na expansão de liberdades ou capacidades (capabilities), ou seja, no alargamento das potencialidades que a pessoa precisa para realizar aquilo que mais valoriza na vida (Sen, 2003: 71). É assim que o desenvolvimento, visto pelo prisma da potenciação ou construção de capacidades (capacity building), acaba por se abrir a uma conceção de educação enquanto empoderamento, isto é, enquanto processo de obtenção, alargamento ou reforço de poderes que estão na base da agency das pessoas, tanto individual como coletivamante consideradas. Dessa forma, e talvez inesperadamente, também abre a «caixa negra» do empoderamento, já que esta noção, simbiotizada com a educação, arrasta consigo uma pletora de significados que é preciso tipificar quando se pretende defender, como é o nosso caso, que a educação pode ser concebida como processo de empoderamento numa ampla perspetiva desenvolvimento humano.

\section{A educação como empoderamento: principais modelos}

A assunção da educação enquanto empoderamento configura uma ressignificação cujas consequências nem sempre se vislumbram com clareza. Em parte isso deve-se ao facto de se tomar a noção de empoderamento sem as devidas cautelas semânticas, pois trata-se de uma noção saturada de ambiguidades resultantes das suas inequívocas conotações políticas. Assim, se queremos redefinir a educação como empoderamento, o que é uma certa novidade no seio das ciências da educação, importa ressalvar, desde o início, que isso nos obriga a delinear vários tipos ou modelos de educação enquanto empoderamento. Ao abrigo da interessante sistematização de significados de empoderamento de Marie-Hélène Bacqué e Carole Biewener (2013), e manejando, com alguma liberdade, as categorizações relativas a esse termo, creio que poderíamos avançar, sem problemas de maior, com três tipos ou modelos de educação enquanto empoderamento: o modelo radical ou integral, inscrevendo-se nas conceções feministas de empoderamento e nas práticas de movimentos populares, onde as práticas de empoderamento visariam a aquisição de poder (amplamente considerado) na ótica socioantropológica da emancipação e da transformação social; o modelo social-liberal, característico dos processos que se articulam com a visão reformista do empoderamento, nomeadamente do empoderamento comprometido com as políticas de modernização ou reinvenção do Estado, ou seja, com as novas formas de regulação e gestão de bens públicos, onde se valoriza o capital social, a inclusão, a cidadania e a participação, mas não a transformação das estruturas que suportam injustiças e desigualdades sociais; e, por fim, o modelo neoliberal, hoje prevalecente nas aceções gerenciais e neoliberais de empoderamento, na medida em que vê esse identificativo da educação como processo individual, e tão só individual, de responsabilização pessoal, de self help, e de capacitação para as escolhas (racionais) que cada um tem que fazer nas diversas esferas ou arenas do mercado.

O empoderamento, do inglês empowerment, é a pedra de toque desses três modelos de educação. Importa, pois, analisar, por referência a tais modelos, o que se entende, verdadeiramente, por empoderamento. Ou seja, que empoderamento é esse que se desdobra, dentro de cada modelo, em significações específicas? Afinal, que é o empoderamento enquanto sinal distintivo, ou imagem de marca, dos modelos de educação que o tomam por referência central e que estamos a propor num exercício algo inovador de reconceptualização?

Antes de mais, e começando pelo significado mais completo, que é o empoderamento no modelo radical? $\mathrm{O}$ empoderamento, no modelo radical, é simultaneamente um processo individual e coletivo cujo objetivo é ajudar os sujeitos a conduzirem as suas vidas e também a emanciparem-se, sendo importante, na linha das teorias de transformação social de Paulo Freire, ou dos ramos mais radicais do movimento feminista, a realização de um processo ou dinâmica de «conscientização» enquanto parte de um processo de ação: «reflete-se para agir, e esta real capacidade de ação é fundamental para uma intervenção de empowerment» (Pinto, 2013: 53). Assente numa consciência da opressão social, das desigualdades na distribuição do poder e dos recursos, esta conceção de empoderamento visa permitir aos indivíduos e aos grupos aumentar o seu poder de agir, desenvolver competências para ganhar influência coletiva e política e para pesar na repartição de recursos sociais. Aqui, conjuga-se a tomada de consciência crítica com o engajamento crítico e político dos sujeitos individualizados e dos grupos articulados.

O empoderamento radical, visto na sua integralidade, articula três dimensões: a dimensão individual ou interior, designando o processo que permite a cada indivíduo desenvolver uma consciência crítica e a sua capacidade de agir, implicando, por esse facto, a construção de uma imagem positiva de si, a aquisição de conhecimento e competências que favoreçam a compreensão crítica do meio, o desenvolvimento de recursos individuais e a elaboração de estratégias para se atingirem objetivos pessoais e coletivos; a dimensão interpessoal, organizacional ou coletiva, designando o desenvolvimento da capacidade de agir em colaboração e em concertação sobre pessoas e recursos do meio envolvente; enfim, a dimensão política ou social, a qual coloca a questão da transformação da sociedade através da ação coletiva, nomeadamente quando é necessário modificar esquemas de poder, e situações geradoras de injustiças, que não se podem atribuir à culpa ou à inépcia dos indivíduos.

Correspondendo a visões reformistas quer da democracia, quer da regulação e da gestão de bens públicos, o empoderamento característico do modelo social-liberal, ou liberal de esquerda, como se poderia designar de outra maneira, não vai tão longe na afirmação do carácter político desse processo, pelo menos não tão longe quanto é desejado pelo empoderamento defendido por organizações feministas e movimentos populares. O empoderamento que aqui está em questão valoriza certamente o reforço dos poderes do 
sujeito, designadamente o poder de fazer escolhas múltiplas e o poder de fazer opções de vida, porém, não chega a questionar as dimensões estruturais das assimetrias ou desigualdades que tolhem certamente muitas oportunidades.

A dimensão social e política do empoderamento, quando está presente, apenas é considerada, como sublinham Bacqué \& Biewener (2013: 94), na «única perspetiva de tornar as instituições mais representativas e de estimular a reforma das políticas públicas, ajudando à construção de coligações em torno deste compromisso». Assim, mesmo que incida na capacitação do sujeito para formas mais democráticas de regulação dos bens públicos, valorizando o capital social, a responsabilidade, a inclusão, a cidadania e a participação, o empoderamento social-liberal é timorato do ponto de vista político e atenua significativamente o sentido radical do empoderamento integral ou multidimensional, nomeadamente o questionamento dos diferenciais de poder que estão na base do desempowering de grupos vulneráveis.

A despolitização do empoderamento, se já é visível no âmbito do modelo social-liberal e, consequentemente, nos programas que lhe dão tradução, seja a nível doméstico, seja a nível internacional, mais evidente se torna no empoderamento que conforma o modelo neoliberal. Como projeto de reforço de poderes ou capacidades, esse empoderamento é estritamente individual. Consiste, antes de mais, em ações de responsabilização dos indivíduos, orientadas, em última instância, para o «self-help» (Bacqué \& Biewener, 2013, p. 45), ou seja, para o cuidado e o socorro de si mesmo. O empoderamento, em tal caso, remete para indivíduos que devem tratar de si mesmos: espera-se que os indivíduos, reforçados na sua capacidade de agir, se insiram no mundo do trabalho e do consumo. Estar empoderado significa ter as capacidades de conduzir a sua vida, de ser empresário de si mesmo, fazendo as escolhas apropriadas para surfar a onda das oportunidades. A promessa emancipadora do empoderamento é aqui colocada ao serviço de um projeto estritamente pessoal focalizado no aumento do bem-estar material numa economia de mercado competitiva. O poder, que constitui a raiz do empoderamento, remete para a liberdade individual, a livre escolha, as oportunidades individuais, que são antes de mais as do mercado. A questão da emancipação individual e da transformação social, características incontornáveis do empoderamento radical ou integral, não são aí colocadas. O que importa, verdadeiramente, não é redistribuir recursos e transformar estruturas consideradas injustas, mas empoderar cada individualidade para que possa ganhar as batalhas da concorrência num mundo cada vez mais competitivo entre pares. $\mathrm{O}$ empoderamento, cingindo-se ao estritamente individual, não tem que almejar outras metas ou objetivos.

À luz destas breves considerações, e ressalvando que se trata de uma hipótese de trabalho, a redefinição da educação como empoderamento não é tão simples quanto se poderia pensar, isto se levarmos em linha de conta que o empoderamento é não poucas vezes apresentado e assumido à margem de conflitualidades políticas e ideológicas. Sendo assim, parece vã qualquer perspetiva de consenso em torno da educação enquanto processo de empoderamento.

\section{Conclusão: elogio do dissenso}

O valor heurístico de uma ressignificação da educação mede-se essencialmente pela abertura de novos horizontes, seja em termos de investigação do campo, seja sobretudo em termos de práticas. Cremos que a ressignificação da educação como processo de empoderamento, ou de empoderamento em processo, cumpre com esses dois requisitos, e especialmente com o segundo, que é, ao fim e ao cabo, o que mais interessa do ponto de vista da promoção do desenvolvimento humano. Dá-se um salto em frente operando essa ressignificação, pois o trabalho pedagógico passaria a incidir naquilo que mais importa à sustentação do desenvolvimento humano: a obtenção, o alargamento e o eventual reforço de poderes ou capacidades sem os quais não há comando ou pilotagem das trajetórias vitais.

Ora, é precisamente isso que se ambiciona com a transmutação da educação em empoderamento, sobretudo se esse empoderamento se assume como integral ou radical, tal como delineado acima. Ou seja, um empoderamento com dimensões individuais, sociais e políticas, por forma a englobar tudo o que faz falta à verdadeira realização dos seres humanos, mormente daqueles cujas posições de subalternidade e sentimentos de impotência estão a impossibilitar o gozo efetivo de um estatuto digno entre o comum dos mortais.

Assim sendo, desfazem-se os sonhos de consenso em termos de educação enquanto empoderamento. A opção é clara: ou aderimos ao modelo que nos permite ter em conta as vertentes que potencializam um desenvolvimento humano verdadeiramente digno e inclusivo, onde todos possam realizar as suas aspirações de seres humanos iguais em direitos, ou enveredamos pelos modelos que, de maneira frouxa ou descarada, nos limitam as potencialidades de emancipação, de justiça e de dignidade entre todos. Esse modelo, como se viu, é o da multidimensionalidade do empoderamento enquanto processo educativo.

\section{Referencias}

Assembleia Geral Das Nações Unidas. Resolução n. ${ }^{0}$ 57/254 (Década das Nações Unidas da Educação para o Desenvolvimento

Sustentável). http://www.mma.gov.br/port/sdi/ea/deds/ pdfs/res254onu.pdf .

Bacqué, M.-H. \& Biewener, C. (2013). L'empowerment: une pratique émancipatrice. Paris: La Découverte.

Castoriadis, C. (2005). Une société à la derive. Entetiens et débats 1974-1997. Paris: Seuil.

Jackson, T. (2011). Prosperidad sin crecimiento. Economía para un planeta finito. Barcelona: Icaria.

Latouche, S. (2011). La voie de la décroissance. Pour une société d'abondance frugal. En A. Caillé; M. Humbert; S. Latouche \& P. Viveret (Eds.), De la convivialité (pp. 43-72). Paris: La Découverte.

Méda, D. (2013). La mystique de la croissance. Comment s'en libérer. Paris: Flammarion. 
Nussbaum, M. (2012). Crear capacidades. Propuesta para el desarrollo humano. Barcelona: Paidós.

Nussbaum, M. (2010). Not for profit. Why democracy needs the humanities. Princeton: Princeton University Press.

Palop, M. (2011). Claves para entender los nuevos derechos humanos. Madrid: Catarata.
Pinto, C. (2013). Uma prática de empowerment com adultos idosos. En M. Carvalho (Coord.), Serviço social no envelhecimento (pp. 49-65). Lisboa: Practor. Pnud (1990). Human Development Report. New York/Oxford: Oxford University Press.

Sen, A. (2003). O desenvolvimento como liberdade. Lisboa:

Gradiva. 